\section{A cognição e os princípios teóricos e metodológicos ao ensino de Libras para ouvintes: orientações a professores iniciantes}

The cognition and the theoretical and methodological principles for teaching Brazilian sign language for listeners: guidelines for beginning teachers

\section{Lídia da Silva (iD) 9}

lidiaufpr@gmail.com

Universidade Federal do Paraná - UFPR

\section{Resumo}

Atualmente, a maioria dos trabalhos relacionados ao ensino de Libras para ouvintes ancora-se na perspectiva social para discutir questões de ordem teórico-metodológica. Este ensaio propõe uma reflexão a partir do viés cognitivo e, para tanto, apresenta princípios teóricos que estão calcados no conexionismo (Mota; Zimmer, 2005; Leite, 2008). Apresenta também princípios metodológicos que se respaldam no modelo computacional de aquisição de L2 de Ellis (1998) àqueles professores com pouca experiência em sala de aula. Nesse modelo, as questões metodológicas ancoram-se na concepção de instrução, sendo que essa pode ser baseada no input, na forma, na produção e no feedback. As instruções são ilustradas com recomendações didáticas encontradas na literatura especializada. Os argumentos apontam para uma visão integrativa entre fatores biológicos e a experiência empírica, e para a indicação de que a instrução formal pode otimizá-los.

\section{Palavras-chave}

Ensino de Libras para Ouvintes; Cognição; Princípios Metodológicos.

\section{Abstract}

Currently, most works related to the teaching of Libras to listeners are anchored in the social perspective to discuss theoretical and methodological questions. This essay proposes a reflection from the cognitive bias and presents theoretical principles that are based on connectionism (MOTA; ZIMMER, 2005; LEITE, 2008). It also presents methodological principles that support Ellis's (1998) those teachers with little classroom experience. In this model, the methodological issues are anchored in the conception of instruction, which can be based on input, form, production and feedback. The instructions are illustrated with didactic recommendations found in the specialized literature. The arguments point to an integrative view between biological factors and empirical experience and to the indication that formal instruction can optimize them.

\section{Keywords}

Teaching Libras to Listeners; Cognition; Methodological Principles.

\section{Linguagęm Foco}

Revista do Programa de Pós-Graduação em Linguistica Aplicada da UECE

FLUXO DA SUBMISSÃO

Submissão do trabalho: $28 / 01 / 2020$ Aprovação do trabalho: $22 / 11 / 2020$ Publicação do trabalho: 22/01/2021

\section{COMO CITAR}

SILVA, Lídia da. A cognição e os princípios teóricos e metodológicos ao ensino de Libras para ouvintes: orientações a professores iniciantes. Revista Linguagem em Foco, v.12, n.3, 2020. p. 197-218. Disponível em: https://revistas.uece.br/index. php/linguagememfoco/article/ view/2630.
Distribuído sob

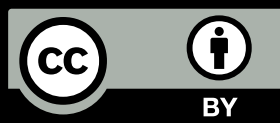




\section{Introdução}

Não é propósito deste texto revisitar argumentos afetivos e sociais que corroboram à aprendizagem de línguas, haja vista que as teorias interacionistas assim já o fazem, de uma forma bastante exponencial. Mesmo no paradigma conexionista, no qual o texto se inscreve, há o entendimento de que fatores como interesse e motivação' do aprendiz são muito importantes e ajudam a recordar o que foi estudado. Diferentemente disso, neste ensaio, pretende-se esboçar algumas considerações cognitivas, que têm gerado estudos frutíferos em diversas áreas da ciência, sendo uma delas a aprendizagem de línguas orais (MOTA; ZIMMER, 2005), que, muitas vezes, passam ilesas pelas discussões em torno do ensino da Libras para ouvintes.

A cognição, como ramo da ciência, apresenta relevante poder explicativo para o fenômeno da aprendizagem e, por isso mesmo, faz-se imprescindível que seus argumentos estejam disponíveis - em uma linguagem menos técnica - àquelas que estão na ponta no processo de ensino e que muitas vezes transpõem para sala de aula constructos de diversas teorias básicas sem que ao menos se saiba suas origens. Essa transposição, por vezes, ocorre de forma indistinta por conta da compreensão "equivocada" de que existem dois mundos sociais diferentes: o mundo dos professores que em sala de aula buscam desenvolver conhecimentos práticos, e o mundo do pesquisador que, dentro dos muros da universidade, busca desenvolver o conhecimento técnico (ELLIS, 1998).

Adiciona-se a isso o fato de que - dado o pouco tempo de consolidação da área de ensino de Libras no Brasil, a ausência de parâmetros curriculares para o ensino da língua, bem como as raras ofertas de formação continuada - os professores carecem de mais diretrizes para nortear sua prática pedagógica.

Partindo disso e levando em conta que as dificuldades dos professores novatos podem ser maiores que as dos professores experientes, propõe-se uma reflexão sobre princípios teóricos e metodológicos ao ensino de Libras para ouvintes, que se ancoram no viés cognitivo, a tais profissionais.

Wilcox e Wilcox (2005, p. 21) também tratam dessa questão e afirmam que "bons professores [...] precisam de orientações curriculares e metodológicas para o ensino". Por isso, pretende-se com este ensaio não somente contribuir, teoricamente, com a questão lacunar da presença da abordagem cognitiva na área de ensino de Libras, mas também contribuir com a formação de professores

1 Nesse caso, a explicação é de que o cérebro quimicamente estimulado desencadeia mudanças que alteram os estados mentais e podem levar ao aprendizado (LEITE, 2008). 
iniciantes de modo que possam desenvolver competências desejáveis para uma atuação efetiva (ROCHA, 2007).

Vale dizer que o professor iniciante a que esse texto se refere, surdo ou ouvinte, trata-se daquele acadêmico que se encontra em formação em nível superior - especificamente falando, no Curso de Licenciatura em Letras Libras, que é o curso no Brasil destinado a formar professores da língua -, ou então o profissional recém-formado que se encontra em suas primeiras atuações em sala de aula.

Em termos metodológicos, o estudo baseou-se nos procedimentos da pesquisa bibliográfica e portanto ateve-se ao conhecimento produzido acerca do conexionismo para a reflexão sobre os princípios teóricos, enquanto que as proposições do modelo computacional de aquisição de L2 guiaram a construção dos princípios metodológicos. Nessa parte, recorreu-se a literatura especializada para, a partir da identificação das congruências de ideias, organizar as orientações didáticas.

Feito esse esclarecimento, apresentam-se as partes que seguem o texto. Na primeira seção, as questões preliminares são trazidas à discussão de modo a situar os sujeitos aprendizes ouvintes e a explicar a particularidade de aquisição de uma língua de modalidade visual-manual. Na segunda seção, de forma bastante resumida, apresentam-se os princípios teóricos que se embasam no paradigma conexionista. Assim foi feito pois, a teoria é bastante complexa e apresenta vários modelos e, por questão de restrição de espaço, a proposta é introduzir o leitor ao assunto para que, convencido de que o aporte pode ser significativo, recorra a referências mais robustas. Na seção 3, baseando-se no modelo computacional de aquisição de L2 de Ellis (1998), apresentam-se os princípios metodológicos para o ensino de Libras a ouvintes. Essa seção recorre a literatura especializada em línguas de sinais para ilustrar os constructos de instrução baseada no input, no ensino explícito, na produção e no feedback. Ao final do texto, encontram-se as considerações finais.

\section{Considerações preliminares}

Considerando que a Libras é uma língua de modalidade visuo-manual, pois é percebida pela visão e articulada por meio das mãos no espaço de sinalização, e que é "oriunda de comunidades de pessoas surdas do Brasil" (BRASIL, 2002), os pesquisadores defendem a ideia de que, apesar e indiferente da idade que houve aquisição pela pessoa surda, ela é sua primeira língua (doravante L L²),

2 Respaldando-se em Gesser (2010), assume-se que L1 é sinônimo de língua materna e língua natural, 
dada a facilidade de acesso ao input (MAYBERRY, 2006).

Por sua vez, quando a pessoa que tem o sentido da audição preservado, chamada de ouvinte, adquire ${ }^{3}$, por várias razões ${ }^{4}$, a Libras, essa pode ser considerada sua segunda língua (L2) ${ }^{5}$, já que o português (uma língua de modalidade oral auditiva) é sua L1. Então, considerando que esses adultos estão aprendendo uma L2 em uma "nova modalidade", tem sido dada a essa língua a designação de L2M2 por alguns pesquisadores, como Picheler e Koulidobrova (2015), por exemplo.

As autoras adotam tal designação, pois dizem que algumas pesquisas linguísticas e cognitivas "descobriram uma série fascinante de potenciais efeitos modais que podem pertencer a uma língua (oralizada ou sinalizada) mas não a outra"6 (PICHELER; KOULIDOBROVA, 2015, p. 219), e que podem afetar o processo aquisional - como a fonologia, por exemplo.

Devido a diferenças óbvias entre o pequeno articulador da língua oral versus os dois grandes articuladores das línguas de sinais, podem ser gerados efeitos na relação L1-L2, e isso implica também em diferenças no processamento sensório-motor e fonológico, o que sugere, portanto, impactos na transferência entre L1 e L2M2. Quer dizer, as experiências anteriores com gestos comuns "podem servir como uma fonte rica de incorporação na sinalização em L2"7 (PICHLER; KOULIDOBROVA, 2015, p. 220).

As autoras explicam que se "prevê que a transferência seja altamente provável"8 nos casos em que a forma do gesto (já usado na L1) seja muito semelhante, mas não idêntica a uma forma L2 (PICHLER; KOULIDOBROVA, 2015, p. 221). Os aprendizes novatos de L2M2 reconhecem sinais que se assemelham aos gestos que eles mesmos usam e, na intenção de substituir a forma gestual pela forma na língua alvo, acabam sinalizando com "sotaque". Isso ocorre, muito provavelsignificando aquela que funciona como meio de socialização familiar.

3 Respaldando-se em Ellis (2005), a aquisição a que esse texto se refere é sinônimo de aprendizagem.

4 Quinto-Pozos (2011) aponta serem essas razões religiosas, acadêmicas, profissionais.

5 Neste texto, assumimos, tal qual Gesser (2010), que L2/LE são intercambiáveis, e que significa uma (ou mais) língua não materna.

6 No original “However, equivalence does not entail being identical, and today's sign language (and cognitive) research has uncovered a fascinating array of potential modality effects that may only pertain to language in one modality (spoken or signed) but not the other."

7 No original "Additionally, other researchers have pointed out that for M2-L2 signers, previous experience with gestures common in hearing communities (e.g., emblems and co-speech gestures but also facial gestures and other nonmanual cues) might serve as a rich source for cross-linguistic incorporation into $L 2$ signing"

8 No original "Perceptual Assimilation model predict that transfer is highly likely in cases where an L1 form is very similar but not identical to an L2 form" 
mente porque os alunos podem não perceber características pequenas, mas linguisticamente significativas, da língua alvo, o que vai resultar em produção de

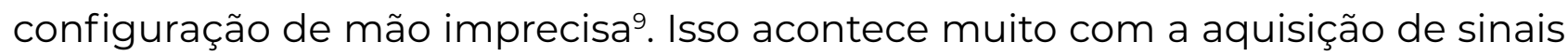
icônicos devido ao fato de haver repertório ${ }^{10}$ gestual incorporado pelo aprendiz.

A relação entre a fonologia e a aquisição da L2M2 também evoca uma relevante discussão ao papel das expressões faciais, as quais compreendem os movimentos de cabeça, a direção do olhar, a elevação das sobrancelhas, a elevação ou o abaixamento da cabeça, o franzir da testa, a postura corporal e os gestos bucais.

Segundo, Quadros, Pizzio e Rezende (2008, p. 3), "as expressões faciais desempenham um papel fundamental e devem ser estudadas detalhadamente". Tais expressões costumam ser separadas em dois grandes grupos: as expressões afetivas e as expressões gramaticais. As afetivas não são exclusivas das línguas de sinais e são utilizadas para referir-se a sentimentos, podendo ou não ocorrer simultaneamente com um ou mais itens lexicais, enquanto as gramaticais atuam no nível morfológico e sintático.

No que diz respeito ao uso da expressão facial pelo aprendiz ouvinte, Leite e McCleary (2009) comentam que, devido a carga gramatical que as expressões faciais têm na Libras, tornam-se um fator complicador" para a aprendizagem e, por isso mesmo, merecem que um tratamento diferenciado seja dado a elas. Silva (2018) também aponta que a expressão facial é um mecanismo extremamente relevante para a fluência em Libras, mas que não parece ser um elemento tão fácil para os ouvintes brasileiros sinalizantes de Libras como L2M2.

O desafio de lidar com essa diferença de modalidade é o que, provavelmente, confere às línguas de sinais a categoria $4^{12}$ de dificuldade. Quinto-Pozos (2011, p 144) menciona que a dificuldade de aprendizado da American Sign Language (ASL) equivale a dificuldade que um falante adulto nativo de inglês tem para aprender chinês ou japonês como uma L2. Devido à distância tipológica

9 Para uma leitura a respeito dos tipos de erros fonológicos cometidos por ouvintes aprendizes de língua sinalizada, ver ROSEN, R. S. Beginning L2 production errors in ASL lexical phonology: A cognitive phonology model. Sign Language \& Linguistics, v. 7, n. 1, p. 31-61, 2004.

10 Para uma leitura a respeito das influências dos gestos na aquisição de língua de sinais por ouvintes, ver JANKE, V.; MARSHALL, C. R. Using the hands to represent objects in space: gesture as a substrate for signed language acquisition. Frontiers in psychology, v. 8, p. 2007, 2017.

11 Os autores apontam outros fatores linguísticos que são difíceis aos alunos ouvintes: a datilologia, o plano morfossintático e os classificadores, e o espaço.

12 Leite e McCleary (2009), ancorando-se em Jacobs (1996), explicam que, devido a essa classificação, sugere-se que o prazo de 6 a 15 anos seja estimado para um falante de língua inglesa adquirir uma alta proficiência em ASL. 
entre Libras e português, Gesser (2010) sugere a mesma causa para a dificuldade de aquisição.

Em virtude do destaque dos efeitos modais durante a aquisição da Libras, neste texto se fará uso da designação L2M2 para referir-se ao aprendiz ouvinte.

\section{Princípios teóricos: a cognição e a aprendizagem de L2M2}

Com base na neurociência, nas décadas de 1950 e 1960 surge o conexionismo que parte da concepção de que o cérebro humano funciona como um computador. Nesse modelo teórico prevalece a ideia de que as informações são armazenadas no cérebro de forma distribuída entre os neurônios que são interligados entre si, o que significa dizer que se estabelece rompimento com a visão modular.

Mota e Zimmer (2005, p. 156) explicam que a ciência cognitiva busca:

caracterizar os processos mentais envolvidos na percepção, apreensão e sistematização dos estímulos aos quais os indivíduos são expostos", [e que] "na psicologia cognitiva contemporânea, esses processos mentais são estudados a partir de dois paradigmas principais, o simbólico e o conexionista (MOTA; ZIMMER, 2005 p. 165)

O interesse deste estudo recai sobre o paradigma conexionista para o qual a relação processamento cognitivo e conectividade neuronial no cérebro é extremamente próxima13".

Essa teoria tenta elucidar como ocorre a aprendizagem a partir da consideração dos efeitos da experiência empírica sobre as redes neuroniais do cérebro. Dito de outro modo, ao conexionismo importa investigar o que acontece no cérebro no ínterim entre estímulo e resposta.

As chamadas conexões ocorrem a partir do "contato" do estímulo externo (visual ou auditivo) com os neurotransmissores, ou seja, trata-se da ocorrência de uma sinapse, momento no qual, segundo Leite (2008, p. 5), "ocorre dois tipos de eventos: um elétrico e outro químico". O elétrico é dado no contato intraneuro-

13 Por uma questão de limitação de espaço, não é possível adentrar à arquitetura anatômica do cérebro, restando apenas lembrar que esse órgão é constituído por 3 estruturas que funcionam de forma interligada: (1) Cortéx cerebral, (2) Cerebelo e (3) Tronco cerebral. O córtex cerebral é dividido em dois hemisférios cerebrais, que comunicam entre si. Os hemisférios esquerdo e direito são conectados pelo corpo caloso. Os hemisférios cerebrais dividem-se em quatro grandes áreas separadas: Lobo frontal, Lobo parietal, Lobo occipital, Lobo temporal. O cerebelo encontra-se na base do córtex e o tronco cerebral faz a ligação entre o cérebro e o resto do corpo. Além dessa estrutura, há também o neocortex, que é como uma "capa" neural que recobre os lóbulos frontais e o sistema límbico que se localiza na zona central do cérebro e inclui o hipocampo, o tálamo, o hipotálamo e a amídala. 
nial, enquanto o químico ocorre quando o estímulo elétrico chega aos ramos terminais. Tais sinapses podem ser mais ou menos intensas, e caso sejam intensas haverá uma marcação positiva na rede neuronial que recebeu o estímulo. Quer dizer, quanto mais se estimula determinada rede neuronial (da mesma forma), mais rapidamente ocorrerão as sinapses. Essas referidas redes estão dispostas em várias localizações do cérebro e, por isso, várias sinapses acontecem simultaneamente (LEITE, 2008).

Mota e Zimmer (2005, p. 165), da mesma forma que Leite (2008), explicam que se os estímulos forem "constantes e repetitivos", então, haverá reforço das sinapses, e isso pode ativar um padrão de processamento da informação. Esses padrões, afirmam as autoras, "formariam a base da memória e do aprendizado".

Aprender (qualquer que seja a habilidade a ser desenvolvida), no paradigma conexionista, significa ativar as redes neuroniais já existentes (aquelas marcadas forte e positivamente) e criar redes novas (através da repetição dos estímulos). Quando da ocorrência das ligações neuroniais dá-se a engramação, mas, mesmo nesse caso (ou seja, quando algo já foi aprendido), as redes permanecem abertas a novos traços - o que ocorrerá à medida que novas conexões forem estabelecidas no mapeamento. Quando Leite (2008, p. 5) comenta que "aprender é alterar as forças das sinapses", a autora está querendo dizer que a experiência empírica está relacionada com as bases físico-químicas do cérebro, que são responsáveis pelo armazenamento, processamento e recuperação das informações.

Dito isso, é preciso pensar: se esse é, basicamente, o escopo do paradigma, então quais seriam os constructos relacionados ao ensino e aprendizagem de L2 e/ou de L2M2?

Em relação à aprendizagem de L2 (e para aquisição de língua em geral) e L2M2, o conexionismo destaca, primeiramente, que as estruturas físicas do cérebro (os neurônios) são inatas, mas, que a abordagem é empirista e, por isso, a aquisição é regida pelos dados disponíveis e não pela genética. Em razão disso, o conexionismo tem servido de inspiração às situações formais de ensino, pois advoga que através de treinamento sistematizado pode ocorrer o processamento dos dados da língua, as sinapses e o aprendizado (LEITE, 2008).

Outro aspecto a se destacar é que nesse arcabouço teórico, no que tange ao ensino e aprendizagem de L2, conforme afirmam Mota e Zimmer (2005), há o entendimento de que a aquisição apresenta gradualidade, e de que a $\mathrm{L} 2$ emerge a partir da interação entre processos biológicos e ambientais. Isso implica na compreensão de que as dicotomias clássicas como natural X social, competência 
X desempenho, memória de trabalho X memória de longo prazo, cedem espaço para uma visão mais integrada de cognição e linguagem. Essa interação explica-se pelo mesmo argumento dado na abordagem funcionalista de que os processos cognitivos levam em conta os fatores biológicos, ao mesmo tempo em que são sensíveis ao contexto (o que se refere, exatamente, à experiência empírica com a língua).

Um importante aspecto que abarca o viés pedagógico do paradigma é o input. O input, nesse contexto, é entendido como sinônimo de experiência empírica com a língua, estimulando uma variação enorme de processos cognitivos no cérebro do aprendiz e, se apresentar frequência e regularidade, favorece a memória de determinada sinapse. Mota e Zimmer (2005) explicam que, desse input, o cérebro processa generalizações que levam à percepção do que nele pode ser considerado padrão - o que pode ser considerado idiossincrático. Tratam-se das mesmas probabilidades realizadas por crianças ao extraírem frequência e saliência dos dados da língua quando se encontram em processo de aquisição da L1. Isso significa dizer que esses dois fatores (frequência e saliência) são os responsáveis pela realização de uma engramação e/ou do seu fortalecimento.

Finalmente, Mota e Zimmer (2005) ainda chamam atenção para a instrução explícita, e dizem que esse é um fator chave para a aprendizagem, sobretudo, no que se refere à oportunidade de monitoramento por parte dos aprendizes e tratamento pedagógico dos desvios.

\section{Princípios metodológicos: o modelo computacional de aquisição de L2 aplicado a L2M2}

Ellis (1998), discutindo a aquisição de L2, propõe uma metáfora. Para o autor, os aprendizes são como máquinas inteligentes que processam os dados na sua caixa mental. Nessa caixa, "contém fios ou mecanismos adquiridos previamente que os permitem internalizar novos conhecimentos e usá-los em tarefas de output"14 (ELLIS, 1998, p. 42), ou seja, trata-se de um computador. O modelo é abaixo ilustrado.

14 No original "This contains wired-in or previously acquired mechanisms that enable learners to internalize new knowledge for use in output tasks." 


\section{Figura 1 - Modelo computacional de aquisição de L2}

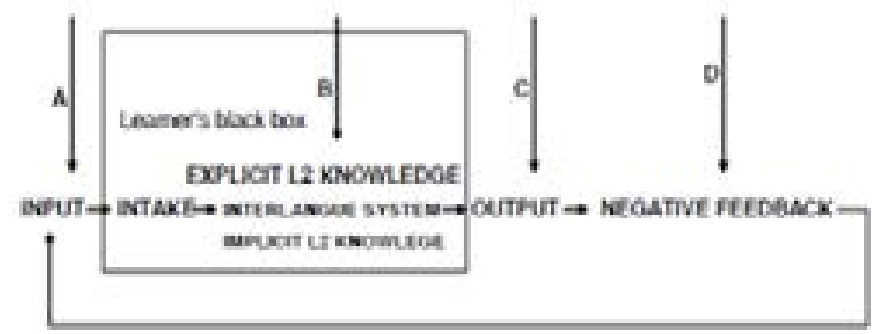

Fonte: Ellis (1998, p. 43).

Falando em termos de aquisição de L2, especificamente, segundo esse modelo, os aprendizes são expostos a determinado input que é absorvido e torna-se intake. O intake transforma-se em conhecimento e é colocado em prática através da produção (output). Quando isso ocorre, recebe feedback negativo e retorna ao início do processo na forma de novo input. Esse processo, didaticamente explicado, ocorre de forma combinada.

O modelo computacional de Ellis (1998) também aponta para estratégias pedagógicas que advêm dessas respectivas posições de processamento. No ponto $A$, há sugestão de que a instrução seja baseada no input. No ponto B, o encaminhamento dá-se em função do ensino explícito. No ponto C, a instrução é baseada na produção, e no ponto D, a instrução é baseada no feedback. Para o autor, essas quatro macro opções podem ser divididas, por professores e pesquisadores, em micro opções, tal qual se fará neste texto para o ensino de Libras como L2M2.

Importa frisar, todavia, que os princípios metodológicos que serão apresentados não se tratam de prescrições de "procedimentos (...) recomendáveis para bem ensinar uma língua", haja vista que "o processo ensino-aprendizagem não é e nunca foi um fenômeno isolado desenvolvido em um vácuo independente de outras influências societais" (GESSER, 2010, p. 2).

Com isso, resta ainda dizer que as propostas de instrução referem-se ao ensino da língua propriamente dito ${ }^{15}$.

15 Diz-se isso pois sabe-se que, antes de ensinar a língua aos aprendizes ouvintes, os professores precisam lidar com aspectos culturais e sócio-políticos, uma vez que os alunos chegam nas salas de aula repletos de falsos conceitos e, por isso, gasta-se bastante tempo fazendo-os desaprender seus pressupostos sobre a língua. Wilcox e Wilcox (2005, p. 44), inclusive, propõem que haja um curso introdutório "onde questões culturais sobre a ASL e os mitos em relação às línguas sinalizadas possam ser examinados", para somente depois ocorrer o aprendizado da língua. Em relação à Libras, isso também acontece. Carneiro (2019) aponta que ainda há muitos estereótipos a serem vencidos em relação à língua e ao surdo, e diz que isso acaba sendo fator de interferência negativa 


\subsection{Instrução baseada no input}

Como já discutido, no conexionismo entende-se que a experiência linguística (acesso aos dados) do aprendiz pode alterar os processos cognitivos, acionando redes, favorecendo sinapses e gerando aprendizado (MOTA; ZIMMER, 2005). Assim, compreende-se que ao professor compete a tarefa de viabilizar tal experiência linguística, quer dizer, é ele quem poderá (também) oportunizar a exposição do aluno ao input linguístico.

Junta-se a esse pressuposto o fato de que Ellis (2005) assevera que os professores precisam maximizar o uso da L2 dentro da sala de aula. Idealmente, isso significa que, na abordagem comunicativa ${ }^{16}$, o lema é apresentar e usar a L2 de forma autêntica, e essa passa a ser não apenas o objeto de estudo, mas também o meio de comunicação. A partir disso, depreende-se que, se a Libras for o meio de comunicação na sala de aula e fora dela, se estará corroborando à instrução baseada no input e assim favorecendo a aprendizagem pelo aprendiz de L2M2.

Em relação à presença real e significativa da Libras em sala de aula, destaca-se que, para tal, o professor precisa fazer uso de comunicação acessível, no sentido de facilitar a compreensão do aluno. No contexto de ensino de ASL, Wilcox e Wilcox (2005) apontam que quando os professores apresentam falas significativamente mais simplificadas do que quando conversam normalmente, há maior compreensão por parte dos aprendizes. E sabe-se que além da simplifica-

no processo de aprendizagem da Libras como L2.Concorda-se com tal afirmação, e compreendese que, de fato, ainda compete ao professor da língua que ensina defender que a língua a qual o aluno está aprendendo é uma língua. Essa é uma questão que pode parecer trivial ou até inexistente em contexto de língua oral, mas, infelizmente, ainda é bastante presente no contexto de ensino de Libras. Além das crenças que precisam ser desmistificadas no ensino de Libras, Carneiro (2019) aponta ainda uma questão atitudinal bastante séria, que é a desconsideração pelo aprendiz de que aprendizagem sempre é lenta e é um processo laborioso. Isso porque, relata o autor, os aprendizes ouvintes se autodenominam intérpretes da língua tão logo terminem os primeiros ciclos de estudos, ao passo que "alunos ingressos em cursos de línguas orais dificilmente acreditam que se tornarão proficientes em pouco tempo" (CARNEIRO, 2019, p. 14). Pensa-se que esse fato também precisa ser tratado pelo professor que assume uma turma de aprendizes de Libras, ou seja, faz-se necessário oferecer o entendimento de que o processo aquisional será longo e demorado. Por fim, ressalta-se que, além de desmistificar crenças e estereótipos em relação ao aprendizado do idioma, o aprendiz de Libras precisa apropriar-se da cultura que subjaz a língua, ou seja, ele precisa "aprender a ver", pois os surdos são "pessoas visuais". Wilcox e Wilcox (2005, p. 17) comentam que "para os estudantes que desejam visitar o mundo das pessoas Surdas, as aulas de ASL são a porta - aprender a ver é a chave!". Partindo desse pressuposto, assume-se que são os professores que precisam ensinar os ouvintes a abrirem a porta.

16 Recomenda-se a leitura de Gesser (2010) para conhecer o histórico das abordagens de ensino e para ter uma noção geral sobre a atual abordagem comunicativa. 
ção, os professores podem recorrer a teatros, gestos e diminuição da velocidade de sinalização para facilitar o processo de aquisição para o aprendiz ouvinte.

Outro aspecto a ser considerado no ensino de L2M2 no que tange à instrução baseada no input é o pressuposto de que, nesse contexto, não haverá o uso de voz. Essa postura deriva de uma política já solidificada em relação ao ensino de língua de sinais e, nos dizeres de Ackerman, Wolsey e Clark (2018, p. 2050), trata-se de um combinado entre alunos e professores de que os ouvintes "devem deixar suas vozes porta à fora"17. Esse combinado também vale para os aprendizes brasileiros (FELIPE; MONTEIRO, 2001, p. 15). Ressalta-se, ainda, quanto a política de "não uso da voz" de que apesar de poder causar certo estranhamento aos alunos ouvintes, o seu uso é indicado "desde o primeiro dia de aula", pois respeita as "crenças linguísticas e culturais da comunidade surda que usa língua sinais ${ }^{18 "}$ (ACKERMAN; WOLSEY; CLARK, 2018, p. 2050).

Infelizmente, a política de "não uso da voz", por vezes, é afrouxada quando se trata de aula sendo ministrada por professores ouvintes. Quinto-Pozos (2011) comenta que isso ocorre em horário de intervalos ou durante um encontro um-a-um, e que essa atitude é muito contraindicada. Concorda-se com o autor, pois entende-se que o professor ouvinte, assim como o professor surdo, deve representar a língua de sinais de forma completa, e que adotar a política de "não uso da voz" favorece o oferecimento de uma experiência cultural autêntica e rica aos aprendizes (ACKERMAN; WOLSEY; CLARK, 2018). Logo, quando o professor ouvinte faz uso da voz, além de ele deixar - naquele momento - de representar a língua e a cultura que ensina, também está limitando a experiência de seus alunos.

É bom lembrar que tal política se refere, exatamente, a "não voz", o que implica na compreensão de que a L1 do aluno pode estar presente, na modalidade escrita - em alguma medida - na sala de aula. Mesmo quando parte-se do pressuposto de que o uso da Ll deva ser evitado a todo custo, há argumentos cognitivos e metodológicos que sustentam a ideia contrária, ou seja, que ela pode maximizar o potencial de aprendizagem da língua-alvo (ROCHA, 2007). Em relação à presença do português escrito nas aulas de Libras, há ainda o argumento da colonialização dos surdos pelos ouvintes. Gesser (2010, p. 59) comenta'9 que

17 No original "Instructors often establish a rule that students leave their voices at the door prior to entering the classroom, including no talking,whispering, or mouthing of words"

18 No original "More importantly, this policy respects the linguistic and cultural beliefs of the Deaf community who use sign language"

19 A autora dedicou sua tese de doutorado a discutir a relação do ouvinte com a escrita do português durante as aulas de Libras. Sugere-se fortemente a leitura do trabalho em GESSER, A. "Um olho no professor surdo e outro na caneta": ouvintes aprendendo a língua de sinais. 219 p. Tese (Doutorado) - Universidade 
o português para a comunidade surda "remete à língua do opressor, do colonizador", mas, avalia que, apesar disso, "tentar coibi-la" durante as aulas de Libras para ouvintes pode significar o desencadeamento de "barreiras emocionais".

Assim, pensa-se que a Libras precisa ser o meio de comunicação com os aprendizes de L2M2 para favorecer a instrução, e isso será um importante estímulo aos seus neurônios, que podem reforçar sinapses e fortalecer os padrões elétricos e, logo, corroborar a aprendizagem (MOTA; ZIMMER, 2005).

Igualmente a esse aspecto, pese-se que a Libras precisa também estar presente em ambientes extraclasse, de modo a servir de input aos aprendizes ouvintes. Consoante a isso, Ellis (2005) incentiva o uso da língua alvo em ambientes fora de sala de aula, afirmando que se o aprendiz restringir-se ao input limitado advindo de aulas semanais será pouco provável que alcance altos níveis de proficiência, ao passo que se expuser a uma porção substancial da L2 - além do aumento da velocidade de aquisição - seu desempenho será significativamente melhor. Felipe e Monteiro (2001, p. 15), de igual modo, afirmam que "não basta ir as aulas" e, por isso, incentivam que o aprendiz busque pelo convívio ${ }^{20}$ com surdos. Outrossim, para Ackerman, Wolsey e Clark (2018), esse convívio, além de fortalecer as habilidades linguísticas, eleva o conhecimento acerca da cultura dos surdos. Sugerem que os encontros extraclasse ocorram em laboratório de língua de sinais, clubes, restaurante, shopping, bares, cafés e associações de surdos. Por conta dessa importância, nos Estados Unidos, explica Rosen (2014), tais encontros são parte integrante dos cursos de ASL ${ }^{21}$.

Sabe-se, todavia, que acompanhar a sinalização em contextos informais é tarefa bastante difícil para o ouvinte. Por isso, Leite e McCleary (2009) sugerem que os cursos de Libras como L2M2 precisam procurar desenvolver essa habilidade nos alunos ouvintes. No paradigma conexionista, essa experiência empírica com a língua é considerada de extrema importância para os processos cognitivos no cérebro do aprendiz de modo que se desencadeiem percepções de probabili-

Estadual de Campinas, Instituto de Estudos da Linguagem, Campinas, SP, 2006.

20 Sabe-se que atualmente as fontes virtuais (tais como youtube e facebook) servem como input aos aprendizes e, inclusive, Ackerman, Wolsey e Clark (2018) devidamente incentivam seu uso. Entretanto, convém orientar aos aprendizes que deem atenção quanto ao consumo de conteúdo desprovido de qualidade linguística, pois essa exposição pode acionar a assimilação, logo, produção de estruturas linguísticas problemáticas. Avalia-se que, nesse caso, compete ao professor indicar fontes de consulta confiáveis.

21 Rossen (2014) explica que nos Estados Unidos é comum haver programas em ASL como língua estrangeira que criam intercâmbio no exterior, em que os alunos visitam membros da comunidade surda em seu país de origem ou em outros países. 
dades, e para que ocorram engramações.

Contudo, a interação em Libras não precisa ocorrer apenas quando há a presença de surdos no espaço. A literatura já aborda a noção de "espaço de sinalização", que se baseia na ideia de um espaço mais cultural do que geográfico, e que devido a isso é moldado pelas interações e relações entre os indivíduos (ROSEN, 2014). Portanto, quando pessoas ouvintes falam em Libras entre si, além de romper com estereótipos a respeito da fala silente 22 e reafirmar sua identidade linguística, criam um espaço de sinalização e mutuamente geram estímulos à aprendizagem.

Em síntese quanto a esse ponto, destaca-se, conforme Vidal (2007), que a instrução baseada no input é uma técnica implícita, quer dizer, quando os aprendizes de L2M2 veem os professores sinalizando de forma clara e lenta e não fazendo uso da voz, quando convivem com surdos em locais sociais e quando sinalizam com colegas ouvintes, não sabem que estão aprendendo, mas estão. Aliás, esses são momentos de uso real e significativo do idioma - o que, sobremaneira, facilita o aprendizado.

\subsection{Instrução baseada no ensino explícito}

Se a instrução anteriormente debatida referia-se a uma técnica implícita, nessa, a abordagem refere-se ao aposto. Trata-se de evidenciar formas linguísticas - extraídas do input - e a elas dar um tratamento explícito (VIDAL, 2007). Nesse ponto, já se assinala que toda a aula de Libras precisa partir de um texto ${ }^{23}$ sinalizado. Isso porque, em concordância com Quinto-Pozos (2011), pensa-se que o ensino da L2M2 precisa proporcionar ao aprendiz exposição aos diversos gêneros do discurso e aos mais variados tipos de sinalização possível com todas as características que Ihes são inerentes. Ainda que Gesser (2010, p. 66) destaque que no início do processo de aprendizagem da L2M2 os alunos ouvintes apresentem muita dificuldade de compreensão de texto sinalizado, avalia-se que, apesar desses esforços cognitivos, essa exposição é uma melhor forma de input do que a exposição a sinais isolados (o que muitas vezes se dá por meio de consulta a

22 Rosen (2014) informa que os ouvintes, em sua maioria, fazem uso da língua de sinais em espaço fora da sala de aula quando estão treinando algum sinal e/ou falando sobre a própria língua, quando estão em ambiente ruidoso ou quando há muita distância entre eles. Por fim, sinalizam também quando querem contar um segredo.

23 Baseando-se em Leite (2010) utiliza-se o termo "texto" como sinônimo de sinalização, de expressão sinalizada, de produção em Libras. 
dicionários e/ou aplicativos de celulares).

Isso porque o ensino isolado de itens lexicais tem sido uma prática recorrente no Brasil, e tem sido problemática, já que por ser descolada de um contexto de uso comunicativo da língua acaba ocasionando defasagens na aprendizagem, o que se reflete, inclusive, em produções disfluentes (QUINTO-POZOS, 2011; SILVA, 2018). Fica, portanto, demarcado que a instrução baseada no ensino explícito que esse texto propõe tem a ver com o destaque a estruturas alvos, tais como aspectos da morfologia e da sintaxe, e não ao trabalho com itens lexicais isolados - ao menos que haja um objetivo instrumental específico para isso. Mayberry (2006) sinaliza que a ausência desses elementos nas aulas de L2M2 pode reverberar em desempenho linguístico insatisfatório por parte do aprendiz, algo que pode ser considerado como pidgin ${ }^{24}$.

O trabalho Foco-na-Forma (FocF), diz Ellis (2005), é eficiente ao ensino de línguas por preparar uma série de processos cognitivos para que os alunos realizem a comparação cognitiva entre o que eles observam no input e no output (o monitoramento, para o paradigma conexionista). Ou seja, trata-se de uma fase intermediária entre a entrada, o processamento e a saída de dados linguísticos. Portanto, sugere-se que esse seja aplicado ao ensino de L2M2.

Mas, exatamente, quais formas precisam ser destacadas durante o ensino explícito? Para Quinto-Pozos (2011) são aquelas construções particularmente difíceis para o aprendiz ouvinte. E o que é difícil, nessa perspectiva que considera o esforço cognitivo e releva os efeitos modais, são exatamente as estruturas marcadas no espaço de sinalização (PICHLER; KOULIDOBROVA, 2015).

O trabalho de Silva (2018) trata do uso de três elementos da espacialização em Libras por ouvintes e sua relação com os níveis de fluência. Para o estudo ora proposto, propõe-se que, para alunos mais avançados no idioma, haja tratativa metalinguística dos elementos.

Do referido estudo, grosso modo, pode-se dizer que os três elementos (associação de pontos no espaço, produção morfossintática e referenciação por meio do corpo), se utilizados de modo satisfatório durante a sinalização de uma narrativa, favorecem maiores níveis de fluência, ao passo que, em caso de uso precário, os níveis de fluência são baixos. Levando em conta essa razão bem como a dificuldade apresentada por ouvintes em sua realização, pensa-se serem essas as formas a se destacar durante as aulas de Libras.

Por uma questão de limitação de espaço, esclarece-se aqui, rapidamente,

24 Trata-se da uma transferência sintática negativa que os ouvintes de L2M2 realizam. No Brasil, esse fenômeno é comumente chamado de "português sinalizado". 
sobre os três elementos abordados pela autora, e fornece-se uma explicação em Libras $^{25}$ que pode ser acessada em vídeo:

(i) A associação de pontos no espaço diz respeito ao emprego do morfema espacial no espaço de sinalização quando da marcação de referentes. Ou seja, o sinalizante precisa organizar o campo de sinalização, definindo pontos arbitrários para os referentes citados, de modo a não referenciálos e retomá-los sempre ao centro. Precisa fazê-lo à direita ou à esquerda, por exemplo. Dessa feita, é possível que se defina um local para um referente em oposição ao outro para que as relações contrastivas sejam destacadas, e é possível também modificar sinais, tipicamente realizados ao centro, para direita e/ou esquerda, de modo a alinhar a semântica com os referentes já deslocados. Nesse interim, o sinalizante também precisa fazer uso de apontação (como recurso pronominal ou anafórico, por exemplo) e das descrições locativas.

(ii) A produção morfossintática ${ }^{26}$ trata sobre o fato de que os ouvintes precisam prestar atenção à sentença que está influenciando a realização verbal. O verbo COMER, por exemplo, tem sua forma modificada a depender do objeto a que se refere. As formas verbais simples, com concordância e espaciais, precisam ser produzidas de modo acurado nos parâmetros fonológicos. E os verbos que indicam ações realizadas com as mãos precisam ser produzidos de forma bastante gestual e representativa para manter a clareza da informação.

(iii) Referenciação por meio do corpo diz respeito à reprodução, através do corpo, das ações e falas dos personagens. Refere-se também à descrição detalhada de suas características físicas, emocionais e psicológicas, e à realização de anaforismos para demonstrar diálogos diretos entre os personagens.

Em síntese a esse ponto, destaca-se que são sobre esses três elementos que o professor precisa encaminhar a instrução baseada no ensino explícito, já que tais formas são imprescindíveis à boa sinalização em Libras. Ademais, pelo assentamento ao viés conexionista, destaca-se que essas estruturas são poucos simplificadas e acarretam muito esforço de processamento. Por isso mesmo, o seu ensino explícito corrobora à aprendizagem da L2M2. Propõe-se fortemente que esse ensino ofereça oportunidade de repetição de modo que se caracterize

25 https://www.youtube.com/watch?v=OFX11i4PTS8\&feature=youtu.be

26 Para uma análise do uso do elemento por ouvintes ver SILVA, L; SILVA, A.R. Verbos manuais em Libras: análise da produção em L2 e contribuições à prática pedagógica. Revista Diálogos, v. 7, n. 2, p. 201-225, 2019. 
por um estímulo que reforce as sinapses e que ative um padrão de processamento bem marcado e, assim, possa fortalecer as engramações da língua alvo dos aprendizes ouvintes (LEITE, 2008; MOTA; ZIMMER, 2005).

\subsection{Instrução baseada na produção}

Como o próprio nome indica, essa instrução implica na criação de oportunidades para que aprendizes possam produzir na língua alvo, e isso pode ocorrer por meio do encaminhamento de tarefas mais controladas ou mais livres (VIDAL, 2007). Nesta abordagem, tem-se o entendimento de que a produção viabiliza o desenvolvimento da interlíngua ${ }^{27}$ e que, portanto, deve haver incentivo para ocorrência acurada.

Vidal (2007) sugere que essas tarefas sejam feitas em pares ou em pequenos grupos, e Gesser (2010) adere a essa ideia e incentiva o professor a usar a prática de diálogos como estratégia didática. Para tanto, é possível amparar-se no argumento de que por meio da conversação entre os aprendizes ocorre não somente a automatização de recursos linguísticos aprendidos, mas também aprendizagem de novos. A cargo desse contexto é que se alega que os professores precisam proporcionar oportunidades variadas para os alunos usarem o idioma, e assim demonstrarem o seu desempenho na língua.

O que está se construindo, então, é o entendimento de que a sala de aula precisa ser interativa, de modo que os aprendizes tenham oportunidade de se expressar na L2M2 que estão aprendendo. Para Ellis (2005), a melhor forma de ordenar as atividades dessa natureza é a proposição de trabalhos em pequenos grupos, sob a precaução de que não haja uso excessivo da L1.

As vantagens de se propor trabalhos em grupo de modo a otimizar a instrução baseada na produção vão desde a consideração de que, por se tratar de interações significativas, a tarefa desencadeia motivação nos alunos, até o fato de que esses trabalhos possibilitam que os alunos monitorem a si e aos seus colegas em relação ao uso da língua, o que pode impactar positivamente a aprendizagem (ROCHA, 2007; WILCOX; WILCOX, 2005).

Quinto-Pozos (2011) sugere que, além de diálogos, os aprendizes realizem produções sinalizadas no gênero monólogo, e que as façam em casa em formato de vídeo. Percebe-se que tal prática, por caracterizar-se como fala semi-espontânea - além de oferecer uma dinâmica temporal diferenciada daquela face-a-

27 O termo interlíngua foi criado por Selinker e refere-se a um estágio intermediário entre a L1 e a L2 do aprendiz. 
-face em que há "exigência" de produção imediata, e, portanto, poder por isso apresentar melhor desempenho, já que o próprio aluno pode refazer, caso ache necessário - também, minimiza possíveis tensões que a troca de turno eventualmente ocasiona. Pelo que se pode notar, em cenário regional, essa prática tem sido bastante recorrente em cursos de Libras para ouvintes. O que permanece desconhecido, todavia, são duas interessantes questões que ainda precisam ser investigadas:

(i) Que "tipo de monólogo", além das narrativas pessoais, os professores têm solicitado aos seus alunos?

(ii) Qual é o resultado que tais produções têm gerado em termos de aprendizagem da Libras?

Acentua-se que tais questionamentos parecem caros à instrução que se baseia, predominantemente, na produção do aprendiz.

Entende-se que, para a primeira questão, a recomendação, tal qual foi feito nas seções anteriores, é de que diversos gêneros podem suscitar temas para sinalização dos alunos: contar uma história, fazer um resumo, descrever uma cena, explicar algum assunto, sinalizar cenas de filmes não verbais, recontar histórias sinalizadas, e outras. Apoia-se, inclusive, que tais atividades possam demandar um conhecimento pouco acima do nível atual ${ }^{28}$ de proficiência do aluno.

Em relação à segunda questão, acredita-se que a contribuição seja, pontualmente, em relação ao sistema articulatório do aprendiz. Quer dizer, a produção a que esta estratégia pedagógica instrucional se refere, como já bastante demarcada neste texto, é L2M2 - o que impele a consideração de que, para além de lidar com os componentes modais, a forma marcada do espaço, os léxicos, a datilologia e tantos outros fatores complicadores da aprendizagem, ao aluno ouvinte também coloca-se o desafio de adquirir um sistema articulatório inteiramente novo (HILGER et al, 2015).

Quanto a isso, Hilger et al (2015) mencionam que as dificuldades motoras de ouvintes aprendizes de L2M2 manifestam-se em sinalizações pouco estáveis, com muita hesitação, repetição, exagero, movimentos corporais incomuns e tensão muscular inadequada. Ocorre que os autores apontam que a destreza motora pode ser melhorada com o tempo. Os resultados de suas investigações apontam que sinalizantes com mais tempo de aquisição da ASL demonstram menos variabilidade na coordenação motora do que aqueles iniciantes no idioma.

Tal constatação se vincula à essa proposta de instrução e, por isso, o prin-

28 Conforme a hipótese $\mathrm{i}+1$ de Stephen Krashen. 
cípio é pela insistência com a produção, ainda que ela se apresente de forma mecânica, pausada e instável. Como esse princípio metodológico assenta-se no conexionismo, mais uma vez, evoca-se a alegação de que estímulos constantes e repetitivos reforçam as sinapses, que ativam um padrão de processamento da informação, o qual forma a memória e o aprendizado (LEITE, 2008; MOTA; ZIMMER, 2005).

\subsection{Instrução baseada no feedback}

Para Vidal (2007), esta instrução está estritamente ligada à anterior, pois consiste em dar feedback corretivo ao detectar um erro ${ }^{29}$ de produção do aprendiz. Através do feedback acerca de sua sinalização, o aprendiz pode incorporar novas formas de aprendizado e, posteriormente, apresentar acurácia e precisão em Libras. Tal encaminhamento pode ser feito de várias formas: por correção explícita, por reformulação, por pedidos de esclarecimento, por feedback metalinguístico ou ainda por repetição.

Mais uma vez, levando em conta o que dizem Mota e Zimmer (2005), compreende-se que os processos cognitivos responsáveis pela emergência da L2M2 são sensíveis ao contexto externo, ao contato com a língua e à experiência linguística. Portanto, infere-se que feedbacks feito por professores aos aprendizes acerca de seu desempenho ${ }^{30}$ são interessantes recursos contribuintes à aprendizagem.

Esses feedbacks podem ser dados em vários momentos (inclusive na instrução baseada no input, no ensino explícito e na produção), mas deverá haver uma oportunidade pontual para que o professor dê retorno claro e objetivo aos alunos acerca de suas produções. Nesse caso, sugere-se que algumas atividades, necessariamente, sejam gravadas (talvez aquelas mesmas utilizadas para o desenvolvimento de monólogos), pois, tendo um vídeo em mãos, o professor pode fazer uma análise mais eficiente da sinalização do ouvinte aprendiz de L2M2.

29 Corder (1967) defende que erros expõem algo a respeito do sistema operacional, sobre a natureza do conhecimento do aprendiz. O autor reconhece que os erros dos aprendizes não devam ser tratados como algo a ser evitado, mas sim considerados como uma característica inevitável do processo de aquisição de L2, ou seja, tratam-se de características normais e inevitáveis que indicam as estratégias que os aprendizes usam quando estão desenvolvendo uma interlíngua. Aliás, o erro não é algo que impede o progresso do aprendiz. Pelo contrário, é indício ativo do seu processamento e evolução no contato com a língua nova.

30 Pensa-se que, no início do processo de ensino, os professores precisam também oferecer instrução baseada no feedback com foco na compreensão, e isso poderá ser feito através de formulação de perguntas do tipo interpretação de texto, tal qual a negociação de sentido, advogada por Long (1983). 
Para tanto, os professores podem fazer uso de um recurso tecnológico que está se tornando uma tendência nos locais que oferecem aulas de ASL nos Estados Unidos. Trata-se do GoReact. ${ }^{31}$ Ackerman, Wolsey e Clark (2018) explicam que essa ferramenta é um software de feedback que foi desenvolvido na Universidade Brigham Young, em 2010, que permite ao receptor do vídeo fazer pausas em dado tempo para então realizar os comentários de feedback. O usuário que posta o vídeo no software (o aprendiz de L2M2, no caso) pode alterar as configurações e definir quem pode visualizar os vídeos, quem pode criar e ver os comentários, e até em que data o vídeo estará disponível. As autoras explicam que, por conta do feedback codificado por tempo, os alunos podem encontrar exatamente onde estão seus erros em suas tarefas, e podem corrigir ou melhorar suas habilidades na língua de sinais - o que traz impactos positivos no aprendizado dos alunos. Essa ferramenta é uma alternativa plausível em relação às modalidades de escrita que fazem menção ao tempo do vídeo do aluno e não permitem uma visualização simultânea entre o dado e o comentário.

Especificamente em relação a quais aspectos considerar na sinalização, o professor precisará estar de posse do objetivo traçado para aquela determinada situação. No caso da sinalização de uma narrativa, por exemplo, pode-se olhar para os três aspectos que compõem a especificidade da modalidade, anteriormente discutidos, com ênfase na habilidade motora e com destaque aos "erros de espelho"32 (PICHER; KOULIDOBROVA, 2015). É bom que se diga que no paradigma conexionista os erros de produção se devem, em grande parte, à distância entre input - output, então, por isso mesmo, o seu tratamento poderá ocorrer mediante instrução explícita (seção 4.2) e exposição a novos inputs (seção 4.1).

Os vídeos apresentados pelos alunos podem ser utilizados como material em sala de aula para que - em obtendo o consentimento para isso - o professor possa publicizar ${ }^{33}$ o que recebeu pelo GoReact e explicitar os efeitos negativos da sinalização, de modo a gerar dados novos que desencadeiem novas engramações (MOTA; ZIMMER, 2005).

31 Uma versão DEMO pode ser obtida pelo link https://get.goreact.com/

32 "Erros de espelho" ocorrem quando os aprendizes falham em rotacionar um sinal de duas mãos na hora de produzi-lo, alterando, por exemplo, a mão dominante e a mão passiva. Picher e Koulidobrova (2015) dizem que há erros frequentes de espelhamento na sinalização L2M2, e sugerem que os sinais assimétricos são os mais desafiadores à percepção dos aprendizes.

33 Uma alternativa a essa exposição é o professor copiar os exemplos dos alunos e exibir a sua própria imagem em vídeo a fim de salvaguardar a identidade do sinalizante da amostra. 


\section{Considerações finais}

No percurso traçado ao longo deste ensaio, buscou-se refletir sobre os princípios teóricos e metodológicos ao ensino de Libras como L2M2. Partindo do pressuposto do conexionismo, passou-se às considerações de instruções baseadas no input, no ensino explícito, na produção e no feedback - sendo que para esses o pano de fundo adotado foi o modelo computacional de aquisição de $L 2$ de Ellis (1998).

Em relação à abordagem teórica do conexionismo, buscou-se enfatizar as relações entre cognição e aprendizagem com ênfase à ideia de interação entre bases físico-químicas cerebrais e experiências empíricas.

Quanto às proposições para a prática pedagógica, enfatizou-se formas de sistematização da experiência linguística do aprendiz, ensejando que essas possibilitem a intensificação das sinapses, de modo que possam ocorrer marcações positivas nas redes neuroniais.

Finalmente, o texto buscou o professor iniciante como interlocutor e, por isso, procurou-se dar uma roupagem teórico-prática ao debate, com a finalidade de juntar os conhecimentos técnicos e científicos na tentativa de aproximar dois mundos distantes. Fez-se isso pois sabe-se que para ambos, professores e cientistas da linguagem, o objetivo é o mesmo: favorecer o desempenho linguístico do aprendiz de Libras como L2M2.

\section{Referências}

ACKERMAN, J. M.; WOLSEY, J.-L. A.; CLARK, M. D. Locations of L2/Ln Sign Language Pedagogy. Creative Education, v. 9, n. 13, p. 2037-2058, 2018. Disponível em https://www.researchgate. net/publication/328499598_Locations_of_L2Ln_Sign_Language_Pedagogy. Acesso 03 dez 2020.

BRASIL. Lei n 10.436 de 24 de abril de 2002, que dispõe sobre a Língua Brasileira de Sinais - Libras. Diário Oficial da União. Brasília: MEC, 2002.

CARNEIRO, B. G. OS SURDOS TAMBÉM FALAM?: ASPECTOS SOBRE LÍNGUA DE SINAIS/CULTURA SURDA PARA ESTUDANTES OUVINTES DE LIBRAS COMO SEGUNDA LÍNGUA. Revista São Luis Orione, v. 1, n. 14, 2019. Disponível em http://seer.catolicaorione.edu.br:81/index.php/revistaorione/article/view/126. Acesso 03 dez. 2020.

CORDER, P. The significance of learner's errors. International Review of Applied Linguistics,S, 161-170. THE SIGNIFICANCE OF LEARNER'S ERRORS, 1967. Disponível em http://www.uky.edu/ tmclay/Corder\%201967.pdf. Acesso 03 dez. 2020.

ELLIS, R. Principles of instructed language learning. System, v. 33, n. 2, p. 209-224, 2005. Disponível em https://www.sciencedirect.com/science/article/pii/S0346251X05000138. Acesso 03 dez. 
2020.

ELLIS, R. Teaching and Research: Options in Grammar Teaching. TESOL Quarterly, v. 32, n. 1, Spring, 1998, p. 39-60. Disponível em https://elanoldenburg.files.wordpress.com/2008/11/ellisteaching.pdf. Acesso 03 dez. 2020.

FELIPE, T. A.; MONTEIRO, M. S. LIBRAS em Contexto, Livro do Professor/instrutor - Curso Básico Programa Nacional de Apoio à Educação de Surdos. Brasília: MEC - SEE, 2001.

GESSER, A. Metodologia de Ensino em Libras como L2. Florianópolis: UFSC, 2010. Disponível em https://www.libras.ufsc.br/colecaoLetrasLibras/eixoFormacaoPedagogico/metodologiaDeEnsinoEmLibrasComoL2/assets/629/TEXTOBASE_MEN_L2.pdf. Acesso 03 dez 2020

HILGER, A. I. et al. Second language acquisition across modalities: Production variability in adult L2 learners of American Sign Language. Second Language Research, v. 31, n. 3, p. 375-388, 2015.

LEITE, A. de S. O paradigma conexionista na aquisição lexical. ReVEL, v. 6, n. 11, agosto de 2008. Disponível em http://www.revel.inf.br/files/artigos/revel_11_o_paradigma_conexionista_na_aquisicao_lexical.pdf. Acesso 03 dez. 2020.

LEITE, T. de A.; MCCLEARY, L. Estudo em diário: fatores complicadores e facilitadores no processo de aprendizagem da Língua de Sinais Brasileira por um adulto ouvinte. Estudos Surdos IV. Petrópolis: Arara Azul, 2009. p. 242-276.Disponível em https://editora-arara-azul.com.br/site/ebook/ detalhes/14. Acesso 03 dez. 2020.

MAYBERRY, R.I. Learning Sign Language as a second Language. In: WOLL, B. (Ed.). Sign Language, Encyclopedia of Language and Linguistics, 2. ed. Oxford: Elsevier, v 6. p. 743-746, 2006. Disponível em https://mayberrylab.ucsd.edu/papers/Mayberry_2ndLangLrng06.pdf Acesso 03 dez. 2020.

MOTA, M.; ZIMMER, M. C. Cognição e aprendizagem de L2: o que nos diz a pesquisa nos paradigmas simbólico e conexionista. Revista Brasileira de Linguística Aplicada, v. 5, n. 2, p. 155-187, 2005. Disponível em https://www.scielo.br/pdf/rbla/v5n2/08.pdf. Acesso 03 dez. 2020.

PICHLER, D. C.; KOULIDOBROVA, H.. Acquisition of sign language as a second language (L2). In: MARSCHARK, M.; SPENCER, P. E. (Eds.). The Oxford handbook of deaf studies in language. Oxford: Oxford University Press, 2015. p. 218-230. Disponível em https://www.researchgate.net/publication/336284706_Acquisition_of_Sign_Language_as_a_Second_Language. Acesso 03 dez. 2020.

QUADROS, R. M.; PIZZIO, A. L.; REZENDE, P. L. F Língua Brasileira de Sinais II. Florianópolis: Universidade Federal de Santa Catarina, 2009.Disponível em https://www.libras.ufsc.br/colecaoLetrasLibras/eixoFormacaoEspecifica/linguaBrasileiraDeSinaisII/assets/482/Lingua_de_Sinais_II_ para_publicacao.pdf. Acesso 03 dez. 2020.

QUINTO-POZOS, D. Teaching American Sign Language to hearing adult learners. Annual Review of Applied Linguistics, v. 31, p. 137-158, 2011. Disponível em: https://pdfs.semanticscholar. org/Oe6a/54dc73020fbld5672077a2c3d7f25b6d17be.pdf. Acesso 03 dez. 2020.

ROCHA, C. H. O ensino de línguas para crianças no contexto educacional brasileiro: breves reflexões e possíveis provisões. DELTA [online], vol.23, n.2, p 273-319, 2007. Disponível em https://www. scielo.br/scielo.php?pid=\$010244502007000200005\&script=sci_abstract\&tlng=pt. Acesso 03 dez. 2020.

ROSEN, R. S. Between-Learners' Outsideof-Classroom Uses of American Sign Language as a Foreign Language. Sign Language Studies, v. 14, n. 3, p. 360-381, 2014. 
SILVA, L. da. Fluência de ouvintes sinalizantes de libras como segunda língua: foco nos elementos da espacialização. Tese (Doutorado em Linguística) - Universidade Federal de Santa Catarina, Centro de Comunicação e Expressão, Programa de Pós Graduação em Linguística, Florianópolis, 2018.

VIDAL, R. T. Ensino-Aprendizagem de Foco na Forma: Retorno ou Recomeço?. The ESPecialist, v. 28, n. 2, 2007. Disponível em https://revistas.pucsp.br/index.php/esp/article/view/6173. Acesso 03 dez 2020

WILCOX, S.; WILCOX, P. P.. Aprender a Ver. Petrópolis: Editora Arara Azul, 2005. p. 44-72. Disponível em https://editora-arara-azul.com.br/site/ebook/detalhes/9. Acesso 03 dez. 2020.

\section{Sobre a autora}

Lídia da Silva - Doutora em Linguística pela Universidade Federal de Santa Catarina. Atualmente é professora efetiva do Curso de Graduação em Letras Libras da Universidade Federal do Paraná. E-mail: lidiaufpr@gmail.com Lattes: http://lattes.cnpq. br/1746912455361495 . Orcid: https://orcid.org/0000-0002-1722-1753 